\title{
An Empirical study on Sales capability and Marketing implementation capability of SMEs in India and their impact on market share
}

\author{
Jayant Brahmane \\ Doctoral Research ScholarNational Institute of Industrial Engineering, Mumbai, India
}

\begin{abstract}
$\overline{\text { Abstract:Research on marketing capabilities and their linkage with business performance can provide a vital }}$ source of knowledge for firms to acquire competitive advantage in an industry. This study attempts to understand the sales capability and marketing implementation capability and its impact on business performance. It focuses on different processes of marketing capability and its effect on market share in B2B set up. The data was analysed by using multivariate analytical tools such as reliability analysis and Pearson correlation analysis. It can be inferred that marketing capabilities result in achieving growth in market share. Market processes and capabilities consist of processes which act as links between the firm and the customer. Hence, to enhance the business performance, firms need to enrich the links between customer and firm. It is, therefore, necessary to undertake a study which can explore different marketing capability processes and link these capabilities with business performance. The proposed research on marketing capabilities aims at delineating the best practices among small and medium enterprises (SMEs) in 'business-to-business' context to produce superior results such as firms' improved performance.
\end{abstract}

Keywords: Sales capability, Marketing implementation capability, business performance, market share, B2B

\section{Introduction}

Marketing capabilities are defined as the integrative processes designed to apply the collective knowledge, skills, and resources of the firm to the market related-needs of the business, enabling the business to add value to its goods and services and meet competitive demands [15, 42]. As per Day [15] concept of capabilities is not new and has existed since 1957 in the form of organisation policies. As capabilities are embedded within the structure of organization, they are hard to identify. Over a period, the focus of capability study moved from the content of the product to the business strategy and now, more concern has been given on the performance outcomes. In the beginning when researchers started working on capabilities, resource-based view theory was taken into consideration. Barney [9] studied resource-based view which states that the variation of a firm's performance is the result of heterogeneity in the levels, value, inimitability and lack of substitutability of its resources. Then the strategic orientation came in the form of market based learning that helped the firm to deploy resources to get maximum benefit in the market environment. The dynamic capability approach was pioneered by Teece et al. [40]. This approach is distinctly based on legacy of resource based view which has shifted from static firm-specific asset to dynamic process of developing capabilities. Now, companies are thinking to invest directly in identifying and investing in marketing capabilities which will give superior performance.

The most distinctive features of market-driven organisations are their mastery in the market sensing and customer linking capabilities [15]. Market based organisational learning has been identified as an important source of sustainable competitive advantage [41,42]. In order to understand capabilities, one needs to understand the processes of interaction and inter organisational learning [14]. In recent years, management scholars emphasised on resource based view and dynamic capability approach [33]. Capabilities of a dynamic nature, aside from being a source of new resources for the company, provide a solid instrument for the organisation's strategies. These capabilities allow the activation and redirection of the complex framework of economic and organisational factors. Dynamic capabilities are key factors in optimising the strategic course of the firm's future [29].

The resource-based view (RBV) of the firm proposes that firm's performance depend on organization specific resources and capabilities. RBV implies specific path dependencies between resources, capabilities, and firm performance. Hence, RBV takes the perspective that valuable, costly to copy firm resources and capabilities provide the key sources of sustainable competitive advantage. Resources can be tangible or intangible, are valuable and no substitutable. They are usually tacit, socially complex, and rare. According to RBV, firm resources lead to capabilities, and capabilities influence performance [9,44]. Marketers have been highly interested in how various strategies and orientations affect company performance. 
Marketing-led strategies are usually based on the principles of growth throughout the product range. The relationship between marketing objectives and manufacturing strategies appears to be a critical factor affecting the success of the organization but the nature of this relationship is not well defined [28]. Effective integration of marketing, product engineering and manufacturing is vital for the successful development and commercialization of new products. Hence, focus on the interface between marketing and research \& development $(R \& D)$ functions is becoming an important area where innovation can be encouraged $[37,26]$.

We first define marketing capabilities for which we investigates their influence on business performance.

i) selling capability, the processes by which the firm acquires customer orders efficiently and effectively using sales personnel $[4,36]$; and ii) marketing implementation capability, the processes by which intended marketing strategy is transformed into realized resource deployments [32,26].Small firms face marketing challenges, which are related to the general characteristics of small businesses, like a limited customer base, limited marketing activity, expertise and impact, reactive rather than planned marketing and difficulties in exploring marketing opportunities [25]. However, in contrast to large firms, small firms can build marketing advantages based on a close relationship between entrepreneur/manager and customers [45]. They are close to their markets, have greater flexibility and can implement decisions much faster.

Appiah-Adu and Singh [5] argue that in small firms, there is not often a need to develop formal procedures to gather and process market intelligence, because they are usually characterised by relatively simple structures, quite cohesive cultures and a limited range of products and customers. These characteristics may, however, enhance the ability of small firms to exploit customer-oriented culture more easily than larger organisations do.

\section{Resource-based view (RBV)}

Resource-based view (RBV) that was initiated in the mid-1980s by Wernerfelt [44] and Barney [8] had later become one of the dominant contemporary approaches to the analysis of sustained competitive advantage. RBV argues that firms will have different nature of resources and varying levels of capabilities. As per Teece $e t$ $a l$. [40] the competitive advantage of firms is seen as resting on competitive processes. RBV views a firm as a bundle of resources and capabilities. According to the RBV, competitive advantage and durable performance differences between firms are accounted for by asymmetric resource endowments with differential productivities [44,8, 33]. Resources and capabilities are embedded in much larger systems [33].

As per Amit and Schoemaker [3], the firm's resources get defined as the stocks of available factors that are owned or controlled by the firm. Resources are converted into final products or services by using a wide range of other firm assets and bonding mechanisms such as technology, management information systems, incentive systems, trust between management and labour etc. These resources consist, inter alia, of know-how that can be traded (e.g., patents and licenses), financial or physical assets (e.g., property, plant and equipment), human capital, etc. Capabilities, in contrast, refer to a firm's capacity to deploy resources, usually in combination, using organisational processes to affect a desired end. They are information-based, tangible or intangible processes that are firm specific and are developed over time through complex interactions among the firm's resources. They can abstractly be thought of as 'intermediate goods' generated by the firm to provide enhanced productivity of its resources. They also provide strategic flexibility and protection for its final product or service. Unlike resources, capabilities are based on developing, carrying, and exchanging information through the firm's human capital. Makadok [30] proposed two distinct mechanisms, resource-picking and capabilitybuilding, for understanding how managers create economic rents for their firms. The mechanism asserts that firms create economic rent by being more effective than their rivals at selecting resources. The other mechanism asserts that firms create economic rent by being more effective than their rivals at deploying resources.

Barney [9] has put forward a popular checklist for this. He identified following as the key characteristics for a resource to be strategically important: i) Valuable - Resources should deliver value to the firm, ii) Rare - Resources that are owned by a large number of firms cannot confer competitive advantage as they cannot deliver a unique strategy vis-à-vis competing firms, iii) Inimitable - Resources can only be sources of sustained competitive advantage if firms that do not possess these resources cannot obtain them, iv) Nonsubstitutable - Resources should be strategically rare and inimitable by competition.According to Day [16], both static and dynamic capabilities theories attempt to explain sustainable differences in the performance of competitive firms. Whereas competitive advantage can flow at a point in time from scarce capabilities, sustainable advantages require dynamic capabilities to create, adjust, and keep relevant the stock of capabilities. A dynamic capability is a repeatable and deeply embedded set of skills and knowledge exercised through a process. It enables the firm to stay synchronized with market changes and ahead of competitors. 


\section{Sales capability}

Increasing sales is crucial to building market share. Hence, sales revenue can be used as the goal for marketing [7]. Marketing and sales yields many positive outcomes including stimulating confrontation, mutual understanding, collaboration and sharing [19]. As per Kotler et al. [27] sales capability consists of training to salespeople, sales support, sales management planning, sales control systems, developing appropriate selling and management skills.

The field sales force is a vital link between organisation and its customers. Sales performance can be measured relative to each company's major competitor and relative to the sales organisation's objective. The performance measure includes sales volume, sales growth, profitability and customer satisfaction [12].

The long-term strategic orientation of the company can play a critical role. This means that setting long-term goals, giving emphasis to long-term results and devoting time and effort to long-term decisions allow marketing and sales to align their vision, decision processes and activities. This makes the company more effective and efficient yielding better market performance outcomes [19]. Piercy et al. [35] identified factors which have effect on sales performance. These factors are: a) an emphasis on customer-orientated selling requiring more varied types and more sophisticated salespeople; b) the need for flexibility and quick decision making requiring structural change away from traditional bureaucratic forms; c) corporate restructuring to remove traditional barriers between manufacturing, sales, logistics, and customers; d) budget restrictions causing greater scrutiny of the sales process for effectiveness and profit contribution; and, e) the need to organise field units to serve different market segments requiring different selling approaches, managerial structures, and compensation systems. The commitment to fulfilling the needs and wants of customers are now commonly held organisational values across the industrial landscape. Salespersons that possess excellent interpersonal skills can significantly boost sales performance [1].

\section{Marketing implementation capability}

Even a great marketing strategy can be sabotaged by poor implementation. Implementation capability is the capability which focuses on strengthening allocation of marketing resources, delivery of marketing programs, translating marketing strategies into action and have a mechanism for quick execution of marketing strategies.

The SME firm is characterized by a relatively simple organizational structure with relatively fewer people in comparison to large enterprises. Hence, it is imperative for SMEs that the structure and the lines of communication are aligned to support the marketing strategy. Once the marketing strategy has been developed, the task changes to one of implementation of strategy. The formulation of marketing strategy is based on mission, vision, industry, competition, market, and organizational analysis. In SMEs, managers must use networks to implement marketing strategies [23].

Implementation refers to the actions performed as a consequence of policy decisions. This is prompted by definition of marketing as a process whereby actions are defined (planned) and then performed (executed) in a way which leads to satisfactory exchanges in the marketplace [31]. Implementation pervades strategic performance. It is a critical link between the formulation of marketing strategies and the achievement of superior organisational performance $[41,34]$. The inter-functional uniqueness can be configured by characterizing it according to their (a) structural characteristics, e.g. the formalisation of marketing and sales in the organisation and the tasks each function performs, and (b) process dimensions, i.e. interfunctional communication, information sharing and collaboration [2]. Marketing strategies only result in superior returns for an organisation when they are implemented successfully.Heyer \& Lee [21] pointed out some problems in strategy implementation and found that most executives believed that within their firms, the strategy was implemented in inconsistent ways with the strategy development. The study also found common problems in implementing the strategy successfully with organisational barriers. These included uneven or inadequate management skills, a poor comprehension of roles, and insufficient coordination across departmental boundaries, unclear lines of accountability, ineffective monitoring, and lack of employee commitment.

\section{Business Performance}

Most firms do collect, analyze, and base decisions upon market-share data. Measurements of market share are used by firms with considerable confidence to determine whether management should continue current policies or whether it should alter its policies if it has lost market position. Top management generally expresses their target in terms of market share, although they may weigh other considerations in their deliberations. The use of market share target assumes similarities between the past and the present and between each firm and the industry as a whole. Market share has become a language for the expression of the market targets by top management. Clark [11] found this dimension of most importance to managers. Since, by definition, changes in market share represent improving or declining performance relative to competitors, it inherently reflects the attainment or loss of competitive advantage. 
Market share measure of performance was chosen not only to replicate proven measures used in past research but also because it's regarded as a performance dimension of primary importance to top corporate and business unit managers. An operationalisation of the "success of business' products and programs in relation to those of its competitors in the market, measured by such items as sales growth in comparison with that of competitors or changes in market share" represents an effectiveness dimension of performance [43]. Performance over the last one year to major competitors is the effective way to measure business performance $[22,38]$. The relative market share growth is the dependent variable used for this research work. Baker and Sinkula [6] have examined the market orientation-performance relationship. In research, they used change in market share as an indicator of firm performance. They show that performance in these studies is most often measured with self-report measures of new-product success, profitability, or market share.

Small firms may not act in truly the market oriented way, but concentrate more on customer orientation.

\section{Research Questions and hypotheses}

Research questions have emerged from the review of literature.

Research Question 1: Does selling capability have a positive effect on business performance?

If sales management is to become more competitive, management practices that improve its effectiveness must be identified and performance hurdles must be eliminated. Otherwise, even competent salespeople will not be able to perform. Training is a vital component for both the initial and ongoing development of the sales representative [7]. By understanding the salesperson performance, the organisation can create various programmes to improve sales performance. Additionally, sales organisations should now treat interpersonal skills as a critical skill component in salesperson recruitment and selection exercises and also in formulating rewards and recognition policies. Another implication is that salesperson management systems can significantly affect salesperson performance. Given the importance of salesperson performance in the sales organisation context where organisations depend upon individual salesperson's contributions for meeting sales objectives, management should make every effort to promote organisational commitment [1].

Sales management would be expected to help the salesperson improve specific selling skill, foster the motivation to perform and ultimately, enhance productivity [4]. As per Kotler et al. [27] sales capability consists of training to salespeople, sales support, sales management planning, sales control systems, developing appropriate selling and management skills. Therefore, it is hypothesized that:

H01: Selling Capability does not have positive relationship with market share.

Research Question 2: Does Marketing Implementation Capability have a positive effect on business performance?

Marketing implementation capability provides an important mechanism for implementing the firm's strategy. As a result, specialized and architectural marketing capabilities are believed to contribute individually to the successful implementation of product-market strategy. Capability integration can arguably provide the firm with the most advantageous deployment of firm resources [17]. Based on these perspectives, the integration of the marketing knowledge capability provides the best opportunity for properly aligning marketing resources with the demands of the various product-market strategies [41].

Implementation capability is the capability which focuses on strengthening allocation of marketing resources, delivery of marketing programs, translating marketing strategies into action and have a mechanism for quick execution of marketing strategies. Competition is more than just learning; it also involves developing the ability to implement quickly. Many companies are reaching out to firms in other industries to learn how they are able to implement faster. This leads to the following hypothesis:

H02: Marketing Implementation Capability does not have strong relationship with market share.

\section{Methodology}

According to the research questions and hypotheses, 3 variables were constructed to carry further analysis, viz. Sales capability, Marketing implementation capability, and Market share. In the current competitive market, relative market share growth is more relevant feature to measure performance. Relative market share works to measure a business against its single, strongest competitor. This is a way of measuring business strength in relation to either a company that is pursuing it or that it is pursuing. It is also a way of knowing where potential threats and opportunities lie. The reason for choosing relative market share, rather than just profits, is that it carries more information than just cash flow. It shows where the brand is positioned against its main competitors, and indicates where it might be likely to go in the future. It can also show what type of marketing activities might be expected to be effective. 


\section{i) Questionnaire Development}

After reviewing different articles on marketing capability with respect to our study, a basic conceptual design was developed. A questionnaire was designed based on similar constructs validated in previous research studies. From previous empirical research studies, framework is transformed into statements/questions. In addition, a link among the objectives of the study and their translation into content is established. Questionnaire was developed in relation to variables that were measured through the items validated in previous studies. However, the final instrument was unique to the extent that it consisted of all relevant items that explained the power of different marketing capabilities of business-to-business SMEs in Indian context. Selected questions from previous studies were taken and dependent variable measured on a 5 point interval scale (5: strongly agree to 1: strongly disagree). Scales are devices used to quantify to measure marketing capability response on a market share variable. After understanding the relationship between the level of measurement and the appropriateness of data analysis from previous studies, the questionnaire was designed.

\section{ii) Establishing Validity}

After a draft questionnaire was ready, validity test were conducted. Based on the objective, validity was established using a panel of experts and a field test. Questions were taken into consideration while designing instrument. Is the questionnaire valid? In other words, is the questionnaire measuring what it intended to measure? Does it represent the content?Is it appropriate for the sample/population?Is the questionnaire comprehensive enough to collect all the information needed to address the purpose and goals of the study?. "Validity concerns the soundness of the inferences based on the scores - that is, whether the scores measure what they are supposed to measure, but also not measure what they are not supposed to measure [24]. Validity can be divided into discriminant and convergent validities. While addressing questions care was taken to couple it with carrying out a readability test to enhance questionnaire validity. Content validity was checked by feedback from 24 experts in the industry. As the questionnaire designed from the past studies it has concurrent validity. Changes were made, as appropriate, based on both a field test and expert opinion. And then pilot testing in Mumbai and Thane districts of Maharashtra, India was conducted.

\section{iii) Establishing Reliability}

Reliability indicates the accuracy or precision of the measuring instrument. The pilot test seeks to answer the question, whether the questionnaire consistently measures what it intends to measures.

Reliability is established using a pilot test by collecting data from 20 pilot samples from the Mumbai and Thane region of Maharashtra state. Data collected from pilot test was analyzed using SPSS 18 (Statistical Package for Social Sciences). SPSS provides two key pieces of information. These are "correlation matrix" and "view alpha if item deleted" column. Then view "alpha if item deleted" column to determine if alpha can be raised by deletion of items. Deleted items that substantially improve reliability. The reliability coefficient (alpha) can range from 0 to 1 , with 0 representing an instrument with full of error and 1 representing total absence of error. A reliability coefficient (alpha) of 0.70 or higher is considered acceptable reliability. From our analysis the cronbach alpha value is 0.899 and split half part 1 is 0.836 and for part 2 is 0.816 this shows that selected items are fit for the study and instrument has good reliability. Total 42 items were retained for the study.

\section{Sample size}

Multistage random sampling was be used for study. A multistage random sample is constructed by taking a series of simple random samples in stages. In a multistage random sample, a large area, such as a state, is first divided into smaller regions (such as districts), and a random sample of these districts is collected. In the second stage, a random sample of smaller areas is taken from within each of the regions chosen in the first stage. Then, in the third stage, a random sample of even smaller areas (such as neighbourhoods) is taken from within each of the areas chosen in the second stage. If these areas are sufficiently small for the purposes of the study, then the researcher might stop at the third stage. If not, may continue to sample from the areas chosen in the third stage, etc., until appropriately small areas have been chosen.

Sample size calculation for capability study given below,

$\mathrm{S}=$ Estimation of Standard Deviation

$\mathrm{S}=5$ (Number of point scale) / ó (No. of standard deviation)

If á $=0.05$ (Level of significance) and 5 point scale with Accepted error of $3.3 \%$

Sample size $(\mathrm{n})=(\mathrm{t}) 2 *(\mathrm{~s}) 2 /$ (d) $2 \quad \ldots \ldots$ [10]

$\mathrm{d}=\left(5^{*} 0.03\right)$

at $\mathrm{t}=1.96$ and $\mathrm{S}=1.167$

$\mathrm{n}=190$ 
For the study sample size of 193 individual firms were considered. Data was collected from three states of India namely Maharashtra, Gujarat and Madhya Pradesh.

\section{iv) Data Assessment}

The approach suggested by Tabachnick and Fidell [39], Hair et al. [20] and Kline [24] was used for analysis of the collected data, including examination of item means, standard deviations, correlation analysis, and factor analysis. Also, path analysis yielded acceptable results.

The test of internal consistency reliability was performed utilizing Cronbach's coefficient alpha [13]. Cronbach's coefficient alphas are greater than the suggested 0.5 value. Therefore, all scales were considered reliable. Together, the above results support the overall reliability and validity of the scale items used to measure the hypothesized constructs. Pearson correlation analysis used to test the hypothesis.

\section{v) Data overview}

Study was conducted in Maharashtra, Gujarat and Madhya Pradesh states of India. Industries selected for study were chemical, pharmaceutical, capital goods, auto components, electrical, and electronic industry. Table 1 gives details about industry wise and state wise data collected.

Table 1: Industry type - state wise data details

\begin{tabular}{|l|l|l|l|l|}
\hline & Maharashtra & Gujarat & Madhya Pradesh & Total \\
\hline Chemical & 16 & 14 & 10 & 40 \\
\hline Electricals & 10 & 10 & 7 & 27 \\
\hline Electronics & 10 & 11 & 9 & 30 \\
\hline Capital goods & 16 & 14 & 12 & 42 \\
\hline Auto components & 9 & 9 & 8 & 26 \\
\hline Pharmaceutical & 12 & 10 & 6 & 28 \\
\hline Total & 68 & 52 & 193 \\
\hline
\end{tabular}

The respondents belonged to the top management and senior management levels in the SMEs having designations such as directors, owner-directors, vice-presidents, and marketing managers. After analyzing the role and overall decision-making ability of the respondent and his position in organisation structure, respondent was selected for filling the questionnaire. Special care was taken to ensure that he/she has served for a longer time in that organisation.

Total 193 useful responses were collected. Out of 1225 dispatched questionnaires, 39 usable responses were received, showing $3.18 \%$ response rate. Out of 193 useful questionnaires, 154 usable questionnaires were collected personally. Details are given in Table 2.

Table 2: Sample data collection

\begin{tabular}{|l|l|l|l|}
\hline B2B SME Sector & Total samples & Personally collected & Received by Courier \\
\hline Chemical & 40 & 32 & 8 \\
\hline Electricals & 27 & 17 & 10 \\
\hline Electronics & 30 & 24 & 6 \\
\hline Capital goods & 42 & 33 & 9 \\
\hline Auto components & 26 & 24 & 2 \\
\hline Pharmaceutical & 28 & 24 & 4 \\
\hline Total & 193 & 154 & 39 \\
\hline
\end{tabular}

While 112 respondents were from top management, 81 were from senior management levels. The average total experience of respondents is 16 years and the average experience in existing organisation is 11 years. The research study focuses on measuring marketing capabilities of manufacturing firms and their impact on business performance in a B2B environment for SMEs and hence, individually industry wise analysis not included as part of conceptualisation.

\section{Data analysis and discussion}

Respondent data were entered into SPSS package, and different statistical techniques were used to analyse the data. Apart from the available descriptive statistics, multivariate analytical methods Pearson correlation analysis used for analysis of data.

\section{Descriptive statistics}

Analysis of mean and standard deviation for marketing capabilities are shown in Table 3 . The study focuses on the development of a number of key variables. The independent variables used are sales capability and marketing implementation capability. The average score was measured using the likert scale of 1-5, where 5 is strongly agree and 1 is strongly disagree, the standard deviation (SD), which summarises the average distance 
of all responses from the mean and the proportion of all respondents that either strongly agreed or tended to agree with each proposition (\% agree).

The mean score for all variables which are, sales capability and marketing implementation capability is 4. This means that on average, respondent tend to agree that they have experienced marketing capabilities effect in business to business setting. However, the difference between the variables is minimal and standard deviations are fairly similar across each variable. The standard deviation is fairly low (0.45), which means that most of the responses are near around the mean and the distribution of responses is fairly normal with responses being fairly evenly distributed either side of the mean.

Correlation analysis was carried out to ascertain the correlation between each marketing capability with relative market share growth. The procedure used to analyse the responses, including the determination of the reliability of the instrument. The questionnaire constructs were tested for their ability to yield a significant factor structure. The instrument could be said to have a high degree of reliability when there is a significant association between responses to each of the attributes.

\section{Reliability analysis}

The most commonly reported estimate of reliability is Cronbach's alpha. This statistic measures internal consistency reliability, the degree to which responses are consistent across the items within a single measure. If internal consistency reliability is low, the content of the items may be so heterogeneous that the total score is not the best possible unit of analysis for the measure. Construct reliability is given in Table 3. Individual marketing capabilities as first-order construct from the survey data and estimated marketing capability interdependence as a second-order construct will be analysed by capturing the covariance among the marketing capabilities.

Reliability statistics shows that Cronbach alpha except for all other capabilities is above 0.6 shows good reliability.

Table 3: Construct reliability

\begin{tabular}{|l|l|l|l|}
\hline Capability & $\begin{array}{l}\text { Average Variance } \\
\text { Extracted }\end{array}$ & $\begin{array}{l}\text { Loading } \\
\text { Range }\end{array}$ & Reliability \\
\hline Sales capability & 84.6 & $0.8-0.86$ & 0.613 \\
\hline Marketing Implementation Capability & 87.33 & $0.79-0.96$ & 0.65 \\
\hline
\end{tabular}

To calibrate the potential performance impact of marketingcapabilities, regression of each firm's marketingcapability profile deviation score onto its business performance will be formulated. For the analysis of Reliability and Pearson correlation analysis, SPSS software was used. Table 4 shows Cronbach's alpha value as 0.899 which means that selected items are fit for study and instrument has good reliability. Using reliability analysis, one can determine the extent to which the items in questionnaire are related to each other and get an overall index of the repeatability or internal consistency of the scale as a whole.

Table 4: Scale Reliability

\begin{tabular}{|l|l|}
\hline Cronbach's Alpha & N of Items \\
\hline 0.899 & 42 \\
\hline
\end{tabular}

\section{Split-Half Reliability}

In split-half reliability all items that measure the same construct are divided randomly into two sets. Then administered the entire instrument to a sample of people and calculated the total score for each randomly divided half. Table 5 shows split half reliability. Split-half reliability for part 1 is 0.836 and for part 2 is 0.816 . This shows that sample has good spit half reliability.

Table 5: Split-Half Reliability

\begin{tabular}{|l|l|l|l|}
\hline \multirow{2}{*}{ Cronbach's Alpha } & Part 1 & Value & 0.836 \\
\cline { 2 - 4 } & Part 2 & Value & 0.816 \\
\hline
\end{tabular}

\section{Hypotheses testing}

Based on literature review and research gaps, following hypotheses were tested to understand marketing capability and their relationship with market share. Table 6 shows Pearson correlation relationship with sales capability and marketing implementation capability.

Table 6: Pearson Correlation Matrix

\begin{tabular}{|l|l|l|l|}
\hline & Sales capability & $\begin{array}{l}\text { Marketing implementation } \\
\text { capability }\end{array}$ & Market share \\
\hline Sales capability & 1 & $0.462^{* *}$ & $0.235^{* *}$ \\
\hline Marketing implementation capability & $0.462^{* *}$ & 1 & $0.346^{* *}$ \\
\hline Market share & $0.235^{* *}$ & $0.346^{* *}$ & 1 \\
\hline
\end{tabular}


**. Correlation is significant at the 0.01 level (2-tailed).

H01: Sales capability does not have positive relationship with market share.

A Pearson correlation analysis was performed at significance level of $\mathrm{p}=0.01 \mathrm{using}$ SPSS to test the hypothesis. A Pearson coefficient with respect to market share is 0.235 (Sales Capability). The result of Pearson analysis is given in Table 6. It is observed that the sales capability has positive correlation with market share and it is statistically significant. This means that null hypothesis cannot be accepted. It proves that firm's selling capability has positive relationship with the market share. As null hypothesis cannot be accepted, the following alternative describes the relationship between sales capability and market share.

H1: Sales capability has positive relationship with market share.

Training increases salesperson's knowledge base and skill level, resulting in higher performance. Only crafting marketing plan and program is not enough but the mechanism of execution and available resources to execute these plans matters a lot for companies aiming to improve business performance.

Following hypothesis is exploring relationship of marketing implementation capability with market share. Marketing implementation gives speed to execute market based strategies. Implementation of plans and programs is the absolute necessity for the success of marketing campaigns which, in turn, provide better business performance.

H02: Marketing implementation capability does not have positive relationship with market share.

A Pearson correlation analysis was performed at significance level of $\mathrm{p}=0.01$ using SPSS to test the hypothesis. A Pearson coefficient with respect to market share is 0.346 (marketing implementation capability). The result of Pearson analysis is given in Table 6. It is observed that the marketing implementation capability has positive correlation with market share and it is statistically significant. This means that null hypothesis cannot be accepted. It proves that firm's marketing implementation capability has positive relationship with market share. As null hypothesis cannot be accepted, following alternative describes the marketing implementation capability relationship with market share.

H2: Marketing implementation capability has positive relationship with market share.

Marketing implementation capability helps organization to systematically translate its programs, plans and strategies into the final outcome. Hence, it is necessary to have regular audits to check whether resources are available with the organization to improve the stated marketing plans. Proper allocation of these resources is necessary for better and systematic execution of marketing programmed.

\section{Conclusions}

Sales and marketing implementation capabilities were identified as influential to business performance.

Investment in skill development of sales personnel helps firms to understand product and customer more closely. Not only this, it also helps salespersons to move from learning curve to experience curve at a faster pace. Such skillful resource supports the growth of market share. In B2B context, implementation of marketing programs is one of the major challenging tasks. Once marketing program is planned, its execution across the country is the major challenge due to much diversity such as language, culture, geography, climatic condition etc. Hence, during implementation the decision makers need to work efficiently and effectively in such diversities so as to meet the customer needs in most efficient manner and achieve increased sales.

The marketing capabilities provide value added knowledge to managers on how business processes turn marketing capability into business performance advantage. Subsequently, this study explains how marketing capabilities lead to growth in market share. Marketing capabilities are inimitable resource and therefore a greater potential source of competitive advantage. Managers should consider individual marketing capabilities as separate investment options but also assess the implications of such investments for the firm's overall set of marketing capabilities. Secondly, for significant potential business performance, organizations need to focus on sales and marketing implementation capabilities and make use of it for the success of the organisation.

\section{Limitations and scope for further research}

This research is based on the conceptual and empirical results combined and interpreted. The study focuses on marketing capabilities of manufacturing industry with respect to chemical, pharmaceutical, electrical, electronics, capital goods and auto ancillaries. Hence, there is a scope to understand marketing capabilities of other sectors in manufacturing industry. Also, there is an ample scope to delineate the marketing capability in a service industry like aviation, hospitality industry and financial services, etc. 
The business performance variable for this study is market share. Other variables such as customer satisfaction and profitability can be used to investigate further.

The present study focuses on B2B setting and hence, there is further scope to investigate capabilities in other settings like consumer goods sector.

\section{References}

[1]. Ahmad, S., Bashir M., and Kitchen P. (2010). The relationship between sales skills and salesperson performance, and the impact of organizational commitment as a moderator: an empirical study in a Malaysian telecommunications company. International journal of economics and management, 4(2), $181-211$.

[2]. Akdeniz, M., Gonzalez-Padron, T., and Calantone, R. (2010). An integrated marketing capability benchmarking approach to dealer performance through parametric and nonparametric analyses. Industrial marketing management, 39, 150-160.

[3]. Amit, R., and Schoemaker, P. J. (1993). Strategic assets and organisational rent. Strategic management journal, 14(1), 33-46.

[4]. Anglin, K., Stolman, J., and Gentry, J. (1990). The congruence of manager perception of salesperson performance and knowledge based measures of adaptive selling. Journal of Personal selling \& Sales management, 10, 81-90.

[5]. Appiah-Adu, K., \& Singh, S. (1998). Customer orientation and performance: a study of SMEs. Management decision, 36(6), 385394.

[6]. Baker, W. \& Sinkula, J. (2005). Environmental marketing strategy and firm performance: effects on new product performance and market share. Journal of the Academy of Marketing Science, 33(4), 461-475.

[7]. Barker, A. (1999). Benchmarks of successful sales force performance. Revue Canadienne des Science de l'administration montreal, 16(2), 95-104.

[8]. Barney, J. (1986). Strategic factor markets: Expectations, luck and business strategy. Management science, 32, $1231-1241$.

[9]. Barney, J. (1991). Firm resources and sustained competitive advantage. Journal of Management, 17(1), 99-120.

[10]. Bartlett, J., Kotrlik, J. and Higgins, C. (2001),"Organisational research: Determining appropriate Sample size in survey research", Information Technology, Learning and Performance Journal, Vol.19 No.1, pp.43-50.

[11]. Clark, B. (2000). Managerial Perceptions of Marketing Performance: Efficiency, Adaptability, Effectiveness and Satisfaction. Journal of Strategic Marketing, 8 (March), 3-25.

[12]. Cravens, D., Grant, K., Ingram., T., LaForge, R., and Young, C. (1992). In search of excellent sales organizations. European journal of marketing, 26(1), 6-23.

[13]. Cronbach, Lee J. (1951). Coefficient Alpha and the internal structure of tests. Psychometrika, 16, $297-334$

[14]. Croom, S., and Batchelor, J. (1997). The development of strategic capabilities - an interactive view. Integrated manufacturing systems, 8(5), 299-312.

[15]. Day, G. (1994). The capabilities of market-driven organizations. Journal of marketing, 58(4), 37-52.

[16]. Day, G. (2011). Closing the marketing capabilities gap. Journal of marketing, 75 (July 2011). 183-195.

[17]. Dutta, S., Narasimhan, O., and Rajiv, S. (1999). Success in high-technology markets: Is marketing capability critical?. Marketing science, 18(4), 547-568.

[18]. Guenzi, P., and Troilo, G. (2006). Developing marketing capabilities for customer value creation through marketing-sales integration. Industrial marketing management, 35, 974-988.

[19]. Guenzi, P., and Troilo, G. (2007). The joint contribution of marketing and sales to the creation of superior customer value. Journal of business research, 60, 98-107.

[20]. Hair, Joseph, F., Black, William, C., Babin, B., Anderson, Rolph, E. (2005), Multivariate data analysis, Fifth edition Pearson Education

[21]. Heyer, S., \& Lee, R. (1992). Rewiring the Corporation. Business horizons, 35(3), 13 -

[22]. Jaworski, B. and Kohli, A. (1993). Market orientation: antecedents and consequences. Journal of marketing, 57 (July), 53 -70.

[23]. Jones, O. And Tilley F. (2003). Competitive advantage in SMEs, Wiley, 1st edition.

[24]. Kline RB (2011). Principles and practice of structural equation modeling (3rd ed.). New York: The Guilford Press.

[25]. Kobylanski, A. (2011). Development of marketing orientation in small and medium-sized enterprises evidence from eastern Europe.

[26]. International journal of management and market research, 4 (1). 49-59.

[27]. Kohli, A., and Jaworski B. (1990). Market orientation: the construct, research propositions, and managerial implementations. Journal of marketing, 54 (April), 1-18.

[28]. Kotler, P., Kellar, K., Koshy A., and Jha, M. (2013). Marketing management: 14th Edition. A south Asian perspective, Pearson,

[29]. Lancaster, G. (1995). Marketing and engineering revisited. Journal of business \& industrial marketing, 10(1), 6-15.

[30]. Lopez, S. (2005). Competitive advantage and strategy formulation: The key role of dynamic capabilities. Management decision, 43(5), 661-669.

[31]. Makadok, R. (2001). Toward a synthesis of the resource-based and dynamic-capabilities views of rent creation. Strategic management journal, 22, 387-401.

[32]. Meldrum, M. (1996). Critical issues in implementing marketing. Journal of marketing practice: applied marketing science, 2(3), 2943.

[33]. Noble, C. and Mokwa, M. (1999). Implementing marketing strategies: developing and testing a managerial theory. Journal of marketing, 63 (October), pp. 57-73.

[34]. Pandza, K., Horsburgh, S., Gorton, K., and Polajnar, A. (2003). A real options approach to managing resources and capabilities. International journal of operations \& production management, 23(9), 1010-1032.

[35]. Piercy, N., and Lane, N. (1996). Marketing implementation: building and sharing real market understanding. Journal of marketing practice: applied marketing science, 2(3), 15-28.

[36]. Piercy, N., Cravens, D., and Morgan, N. (1997). Sources of effectiveness in the business-to-business sales organization. Journal of Marketing Practice: Applied marketing science, 3(1), 45-71.

[37]. Shapiro, B., Slywotzky, A. and Doyle, S. (1997). Strategic sales management: a boardroom issue. Strategy and Bu siness, 8(1), pp. 29-36.

[38]. Shaw, C., Shaw, V., and Enke, M. (2004). Relationships between engineers and marketers within new product development: an Anglo-German comparison. European journal of marketing, 38(5/6), 694-719.

[39]. Slater. S. and Narver J. (1995). Market Orientation and the learning organization. Journal of marketing, 59 (3), $63-74$.

[40]. Tabachnick, B. and Fidell, L (2001), Using Multivariate statistics, Fourth edition, A Person Education Company.

[41]. Teece, D., Pisano, G., and Shuen, A. (1997). Dynamic capabilities and strategic management. Strategic management journal, 18(7), 509-533. 
An Empirical study on Sales capability and Marketing implementation capability of SMEs in .....

[42]. Vorhies, D., and Morgan, N. (2005). Benchmarking marketing capabilities for sustainable competitive advantage. Journal of marketing, 69(1), 80-94.

[43]. Vorhies, D., Harker, M., and Rao, C. (1999). The capabilities and performance advantages of market-driven Firms. European journal of marketing, 33(11/12), 1171-1202.

[44]. Walker, O. and Ruekert, R. (1987). Marketing's role in the implementation of business strategies: a critical review and conceptual framework. Journal of marketing, 51 (July), 15-33.

[45]. Wernerfelt, B. (1984). A resource-based view of the firm. Strategic management journal, 5(2), 171-180 